\title{
Electrochemical Determination of Melamine on Static Mercury Drop Electrode and on Gold Nano Particle Modified Carbon Paste Electrode
}

\author{
Milan K. Dey, Ashis K. Satpati*, A. V. R. Reddy \\ Analytical Chemistry Division, Bhabha Atomic Research Centre, Mumbai, India \\ Email: ${ }^{*}$ asatpati@barc.gov.in
}

Received 15 April 2014; revised 28 May 2014; accepted 17 June 2014

Copyright (C) 2014 by authors and Scientific Research Publishing Inc. This work is licensed under the Creative Commons Attribution International License (CC BY). http://creativecommons.org/licenses/by/4.0/

(c) () D Open Access

\begin{abstract}
An electrochemical method was developed for the determination of melamine $(2,4,6$ triamino1,3,5-triazine) on static mercury drop electrode (SMDE) and on gold nano particle modified carbon paste electrode. Interaction of melamine with $\mathrm{Cu}^{2+}$ ion was investigated and the decrease of $\mathrm{Cu}$ stripping peak was measured for the determination of melamine using SMDE. Oxidation property of melamine was improved using gold nano particle modified carbon paste electrode. Direct determination of melamine was proposed from the oxidation peak with three sigma detection limit of $0.43 \mu \mathrm{ML}^{-1}$. Recovery in milk powder sample has shown good recovery of melamine using the modified carbon paste electrode.
\end{abstract}

\section{Keywords}

Gold Nano Particles (AuNPs), Carbon Paste Electrode, Melamine, Voltammetry

\section{Introduction}

Melamine is a nitrogen rich compound with around 66\% of nitrogen, which has attracted its use as adulterant in milk and milk products. Melamine is reported to be toxic and damages kidney by formation of needle like crystal when it combines with cyanuric acid. It has lots of industrial uses like, in packaging industry, synthesis of resins and in fire retardant products. Thus, it has been a concern to determine melamine in milk and milk related samples and in water sample. There are some reports of determination of melamine based on chromatography,

"Corresponding author.

How to cite this paper: Dey, M.K., Satpati, A.K. and Reddy, A.V.R. (2014) Electrochemical Determination of Melamine on Static Mercury Drop Electrode and on Gold Nano Particle Modified Carbon Paste Electrode. American Journal of Analytical Chemistry, 5, 598-603. http://dx.doi.org/10.4236/ajac.2014.59067 
[1]-[3] colorimetry [4] [5] and electrochemistry [6]-[8]. Most of the electrochemical procedures reported are indirect determination, based on the variation of electrochemical signal of any other electrochemically active compound in presence of melamine. Cao et al. [6] have reported the decrease in the ferricyanide signals due to the presence of melamine on oligoneucleotide modified gold electrode for the determinations of melamine. Liao et $a l$. [7] have reported the oxidation of uric acid as the recognition signal on screen printed electrode for the determination. In another report, electrochemical signal of ascorbic acid was used as the recognition signal in carbon nano tube (CNT) modified electrode for the determination [8]. Response from the direct electron transfer process in melamine is quite poor [9]. In the present investigation SMDE was used for the indirect determination of melamine in which the change in the stripping current due to the interaction between $\mathrm{Cu}^{2+}$ and melamine was used for the measurements. Carbon paste electrode was modified with AuNPs and it was used for the direct electrochemical signal generation from melamine. Recently there is an article on the determination of melamine from the decrease in the electrochemical signal from potassium ferrocyanide on gold nano particle modified indium tin oxide (ITO) electrode [10]. Determination of melamine using electrochemical techniques is becoming popular [11] [12]. Melamine was determined from the reduction signal of bismuthyl chloride by pre-concentrating it on a carbon composite electrode by solid phase micro-extraction [11] [13]. It was also determined in quail egg and milk samples by capillary zone electrophoresis [12] [14]. In the present study, gold nano particle modified electrode is used but the measurements are based on direct oxidation of melamine which is the primary objective of the present work. Easy renewability of the carbon paste electrode in the present case has the additional advantage to use the method in regular analysis.

\section{Experimental}

\subsection{Instrumentations and Procedures}

Electrochemical studies were carried out using the cell assembly with a three-electrode configuration consisting of the SMDE or modified carbon paste electrode as the working electrode and saturated calomel electrode (SCE) as the reference electrode. The potentials applied, measured and reported in this study were with respect to the SCE reference electrode. A platinum rod served as the counter electrode. All the experiments were carried out at room temperature $(298 \mathrm{~K})$. Electrochemical measurements were performed using an Eco Chemie Potentiostat/Galvanostat, Autolab-302N; the data acquisition and analysis were carried out by GPES 4.9 software. For the measurements with SMDE, 663 VA stand from Metrohm was used. Prior to the electrochemical scan, voltammetric solution was purged with high purity nitrogen gas for $10 \mathrm{~min}$.

\subsection{Reagents and Solutions}

Melamine was purchased from E. Merck India Ltd. Acetic acid, boric acid and phosphoric acid were also of E Merck A R Grade. Auric Chloride was of high purity BDH Aristar grade. Ultra pure water was used for preparation of all the solutions.

\section{Results and Discussion}

Electroanalytical method was developed for the determination of melamine in two ways first by using SMDE as the working electrode and second by using modified carbon paste electrode and the methods were described in the following sub-sections.

\subsection{Determination of Melamine Using SMDE Using It's Interaction with $\mathrm{Cu}^{2+}$}

Melamine has strong interaction with $\mathrm{Cu}^{2+}$, which generates electrochemical signals. These electrochemical signals could be a measure of melamine concentration [9]. However a clear electrochemical signal for quantitative detection of melamine was not attempted previously. We have explored for the quantitative determination of melamine by monitoring the stripping signal of copper in linear sweep stripping voltammetry using SMDE. Anodic stripping voltammetry of copper was carried out with deposition potential of $-1.0 \mathrm{~V}$ for $10 \mathrm{~s}$ and then the potential was scanned from $-1.0 \mathrm{~V}$ to $0.2 \mathrm{~V}$. The stripping peak due to the oxidation of $\mathrm{Cu}$ was observed at around $0 \mathrm{~V}$ as shown in Figure 1. Melamine was gradually added in the test solution containing $3.3 \mu \mathrm{ML}^{-1}$ of $\mathrm{Cu}^{2+}$. During the electrochemical scan $\mathrm{Cu}$ was stripped into the solution as $\mathrm{Cu}^{2+}$ ion. The original Cu stripping peak current was gradually decreased with the addition of melamine and a new pre-peak at more negative potential 


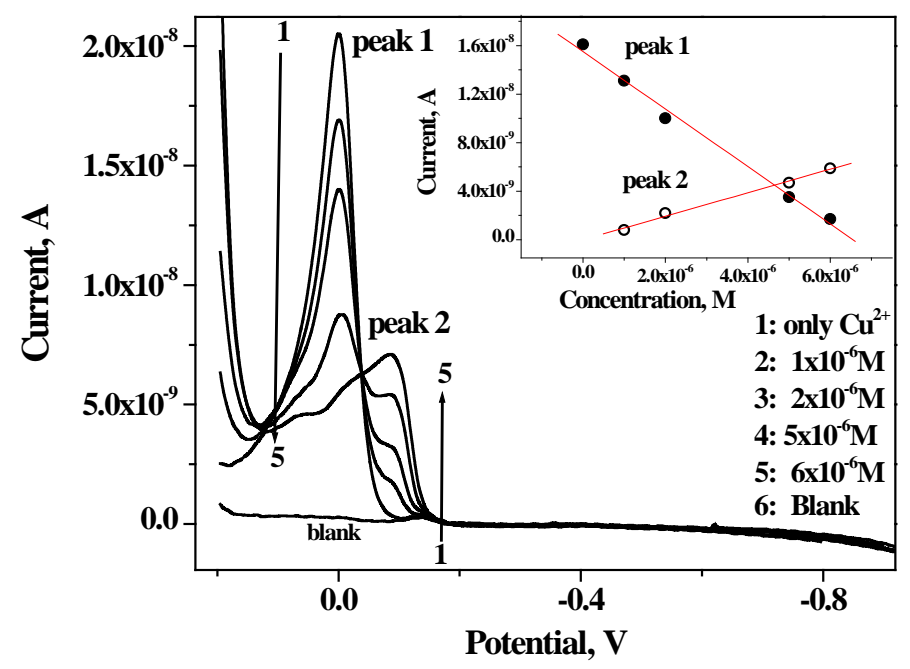

Figure 1. Linear sweep anodic stripping voltammetry of $3.3 \mu \mathrm{ML}^{-1}$ of $\mathrm{Cu}^{2+}$ with different concentration of melamine. Deposition potential was $-1.0 \mathrm{~V}$ for $10 \mathrm{~s}$. Inset: corresponding linear calibration plot of peak 1 and peak 2 .

to that of the Cu stripping peak was appeared. A calibration plot was constructed from the decrease in the stripping peak of copper which was shown in the inset of Figure 1 (peak 1). The calibration plot followed the linear regression equation $\mathrm{i}_{\mathrm{p}}=1.55 \times 10^{-8}-2.37 \times 10^{-3} \mathrm{C}$ with correlation coefficient of 0.998 and standard deviation of $6.15 \times 10^{-10}$, C in molar concentration. The three sigma detection limit from the linear calibration plots was obtained as $0.778 \mu \mathrm{ML}^{-1}$. For indirect determination of melamine this measurement was most workable procedure to determine melamine as it is very easy to obtain reproducible mercury drop for regular analysis. The new peak which was appeared at $-0.09 \mathrm{~V}$ was found to be increased proportionately with the melamine concentration, corresponding linear calibration plot was shown in the inset of Figure 1 (peak 2) The calibration plot followed the linear regression equation as $i_{p}=-7.05 \times 10^{-12}+9.71 \times 10^{-4} \mathrm{C}$ with correlation coefficient of 0.996 and standard deviation of $2.503 \times 10^{-10}$, C in molar concentration. The three sigma detection limit from the linear calibration plots was obtained as $0.773 \mu \mathrm{ML}^{-1}$. It was observed that both the decrease in the stripping peak and the increase in the pre-peak generated similar proportionality and the detection limits obtained from both the ways were similar. This indicated that the type of interaction responsible for the decrease in the stripping current of $\mathrm{Cu}$ and generation of a new pre-peak was the same. Though melamine could be detected indirectly by monitoring the stripping signal of $\mathrm{Cu}$, our aim was to detect the direct oxidation signal of melamine. Thus we have investigated further to measure the oxidation signal directly generated from the oxidation in the melamine centre. Corresponding results were discussed in the following sub-section.

\subsection{Determination of Melamine from Its Direct Oxidation on Modified Carbon Paste Electrode}

Electro-oxidation of melamine produces poor electrochemical response. Previous reports claimed at week electrochemical response due to the oxidation of melamine, which was observed only at neutral to alkaline solutions [9]. Gold has strong interaction with melamine [13]-[16]. However the oxidation peak due to melamine was not observed on bulk gold electrode. Thus, AuNPs modified electrode was preferred for the investigation with the aim to improve the electrochemical response of melamine, especially its oxidation signal. Carbon paste was used as the substrate due to the advantage of easy renewability on regular applications. Carbon paste electrode was prepared in our laboratory and procedure was followed as reported by the previous reports and also the reports from our group [17]-[22]. Carbon paste electrode was modified with AuNPs by electrodeposition method. Electrodeposition of AuNPs over carbon paste electrode surface was carried out from auric chloride solution of 1 $\mathrm{mM}$ concentration. Deposition was carried out at $-0.3 \mathrm{~V}$ for $300 \mathrm{~s}$. Deposits were characterized using SEM; corresponding micrograph was shown in Figure 2. Sizes of most of the deposits were in the range of 100 to 120 $\mathrm{nm}$ with some occasional smaller deposits of around $30 \mathrm{~nm}$. 
This AuNPs modified carbon paste electrode was used for melamine oxidation, corresponding square wave voltammetric plots were shown in Figure 3. Schematic representation of the oxidation process of melamine on AuNPs modified carbon paste electrode was shown in Scheme 1. Voltammetric signal was increased with increase in the melamine concentration in the test solution. Calibration plot was shown in the inset of the Figure 3. Two calibration regions were observed one at low and the other at high concentrations. Three sigma detection limits using this procedure was obtained as $0.43 \mu \mathrm{ML}^{-1}$. Present method was free from interferences form the metal ions like, $\mathrm{Cu}^{2+} \mathrm{Ag}^{1+}, \mathrm{Pb}^{2+}, \mathrm{Bi}^{3+}, \mathrm{U}^{6+}$, and $\mathrm{Hg}^{2+}$ at 100 fold higher concentration than melamine. This is the biggest advantage of detection of melamine using its direct oxidation signal. In the case of indirect determination using $\mathrm{Cu}$ stripping signal the method has the problem interference due to the presence of $\mathrm{Ag}^{1+}, \mathrm{Pb}^{2+}$ and $\mathrm{Bi}^{3+}$ at 10 times higher concentrations.

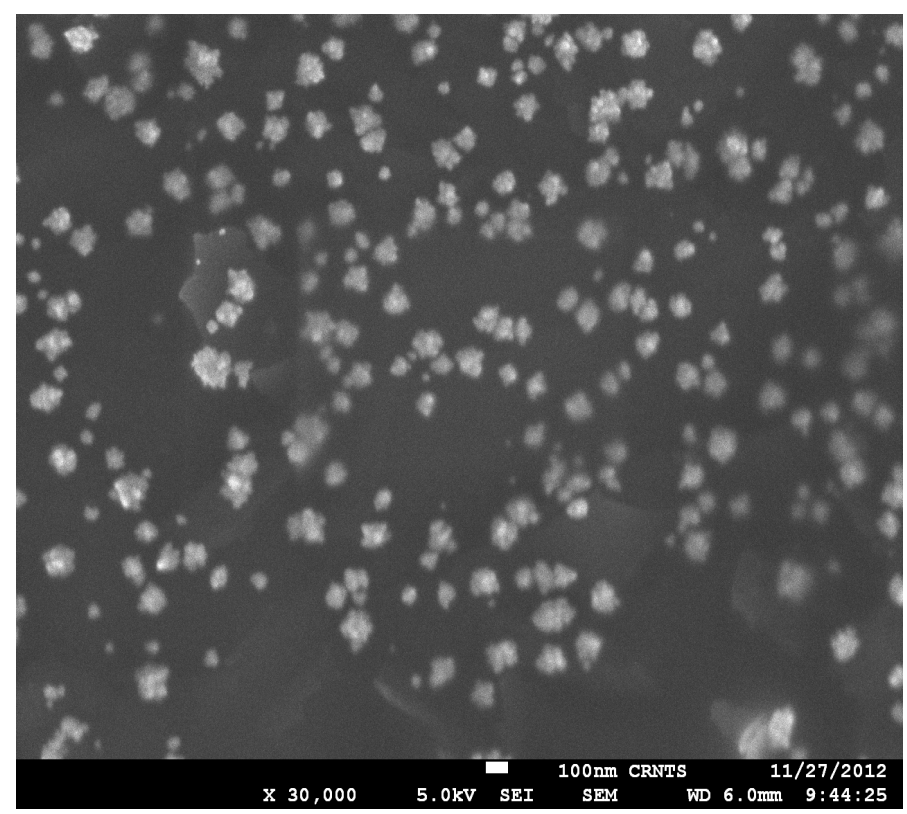

Figure 2. SEM miscrograph of gold nano particles electrodeposited on carbon paste elctrode substrate.

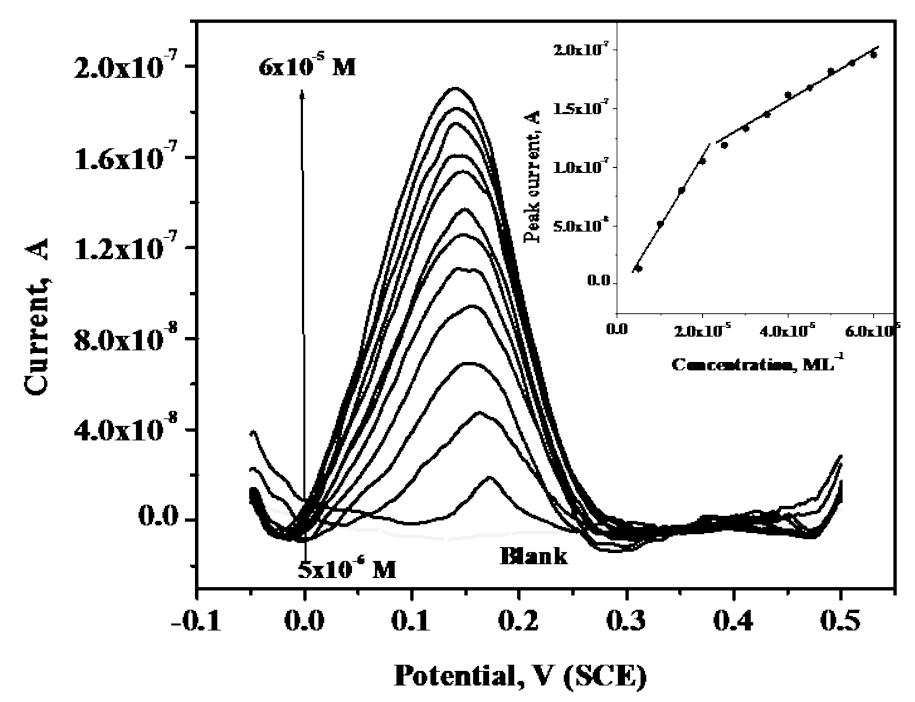

Figure 3. Voltammogram of melamine on AuNPs modified carbon paste electrode with successive addition of $0.5 \mu \mathrm{M}$ melamine. Inset: Corresponding calibration plot. 


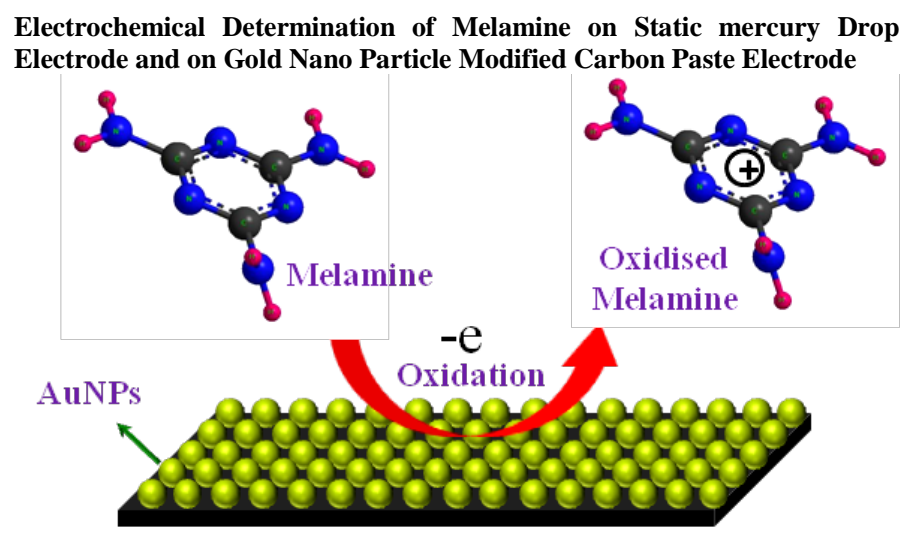

Carbon Paste

Scheme 1. Schematic representation of the oxidation of melamine over AuNPs modified carbon paste electrode.

Table 1. Recovery test result of melamine in milk sample using gold nano particle modified carbon paste electrode.

\begin{tabular}{ccc}
\hline Melamine added & Melamine recovered & \% Recovery \\
\hline $2.0 \mu \mathrm{ML}^{-1}$ & $2.2 \mu \mathrm{ML}^{-1}$ & $110 \%$ \\
$5.0 \mu \mathrm{ML}^{-1}$ & $5.4 \mu \mathrm{ML}^{-1}$ & $108 \%$ \\
\hline
\end{tabular}

Recovery test was carried out by adding known amount of melamine in milk powder sample. Milk sample was treated by taking $1 \mathrm{~g}$ of milk powder mixing with $5 \mathrm{~mL} 0.1 \mathrm{ML}^{-1} \mathrm{CaCl}_{2}$, then $5 \mathrm{~mL}$ of $0.5 \mathrm{ML}^{-1}$ trichloroacetic acid and $35 \mathrm{~mL}$ of $5 \mathrm{ML}^{-1}$ methanol was added. After $10 \mathrm{~min}$ of ultra-sonication, this mixture was centrifuged and the solution was filtrated, through a $0.45 \mu \mathrm{m}$ membrane to obtain the samples for detection of melamine [23]. Electrochemical measurements were carried out using this filtrate. Recovery test results were shown in Table 1. Recovery test result has shown good recovery of melamine in milk sample, recovery within $10 \%$.

\section{Conclusion}

We have developed analytical methods for the determination of melamine in two ways. On SMDE the advantage was the very easy regeneration of the electrode using Metrohm VA 663 stand. This method is useful for the determination of melamine in the laboratory. However, this procedure was based on the indirect measurements using the interaction of melamine with $\mathrm{Cu}^{2+}$. Oxidation response due to melamine was enhanced with the use of gold nano particle modified carbon paste electrode. Monitoring the oxidation signal has produced a high sensitive method of determination of melamine with three sigma detection limit as $0.43 \mu \mathrm{ML}^{-1}$. Measurements based on the AuNPs modified carbon paste electrode have the potential to use as potable sensor of melamine and for field application.

\section{References}

[1] Filigenzi, M.S., Puschner, B., Aston, L.S. and Poppenga, R.H. (2008) Diagnostic Determination of Melamine and Related Compounds in Kidney Tissue by Liquid Chromatography/Tandem Mass Spectrometry. Journal of Agricultural and Food Chemistry, 56, 7593-7599. http://dx.doi.org/10.1021/jf801008s

[2] Wang, H., Liu, Y.Q., Cao, H., Yang, H.M., Liu, X.L. and Yan, L.B. (2008) Determination of Melamine in Pet Food by SPE-HPLC. Chinese Journal of Analytical Chemistry, 36, 273-274.

[3] Andersen, W.C., Turnipseed, S.B., Karbiwnyk, C.M., Clark, S.B., Madson, M.R., Gieseker, C.M., Miller, R.A., Rummel, N.G. and Reimschuessel, R. (2008) Determination and Confirmation of Melamine Residues in Catfish, Trout, Tilapia, Salmon, and Shrimp by Liquid Chromatography with Tandem Mass Spectrometry. Journal of Agricultural and Food Chemistry, 56, 4340-4347. http://dx.doi.org/10.1021/jf800295z

[4] Wei, F., Lam, R., Cheng, S., Lu, S., Ho, D. and Li, N. (2010) Rapid Detection of Melamine in Whole Milk Mediated 
by Unmodified Gold Nanoparticles. Applied Physics Letter, 96, Article ID: 133702. http://dx.doi.org/10.1063/1.3373325

[5] Bera, R.K. and Raj, C.R. (2011) Naked Eye Sensing of Melamine Using Rationally Tailored Gold Nanoparticles: Hydrogen-Bonding and Charge-Transfer Recognition. Analyst, 136, 1644-1648. http://dx.doi.org/10.1039/c0an00870b

[6] Cao, Q., Zhao, H., Zeng, L., Wang, J., Wang, R., Qiu, X. and He, Y. (2009) Electrochemical Determination of Melamine Using Oligonucleotides Modified Gold Electrodes. Talanta, 80, 484-488. http://dx.doi.org/10.1016/j.talanta.2009.07.006

[7] Liao, C.W., Chen, Y.Ru., Chang, J.L. and Zen, J.M. (2010) A Sensitive Electrochemical Approach for Melamine Detection Using a Disposable Screen Printed Carbon Electrode. Electroanalysis, 23, 573-576.

[8] Fotouhi, L., Farzinnegad, N., Heravi, M.M. and Khaleghi, Sh. (2003) Study the Electrochemical Reduction of Some Triazines in N,N-Dimethylformamide at Glassy Carbon Electrode. Bulletin of Korean Chemical Society, 24, 17511756. http://dx.doi.org/10.5012/bkcs.2003.24.12.1751

[9] Zhu, H., Zhang, S., Li, M., Shao, Y. and Zhu, Z. (2010) Electrochemical Sensor for Melamine Based on Its Copper Complex. Chemical Communications, 46, 2259-2261. http://dx.doi.org/10.1039/b924355k

[10] Zhu, Y., Zhang, Y., Li, J., Han, Y., Dong, G. and Zhang, H. (2011) Determination of Melamine in Fresh Milk by Electrochemistry with Solid Phase Microextraction at Bismuthyl Chloride Modified Graphite Epoxy Composite Electrode. American Journal of Analytical Chemistry, 2, 612-618. http://dx.doi.org/10.4236/ajac.2011.25069

[11] Kong, Y., Wei, C., Wang, Z., Hou, Z., Li, H., Yu, J., Yuan, J., Zhao, Y., Long, J., Tang, Y. and Gao, M. (2014) Determination of Melamine in Quail Egg and Milk with Capillary Zone Electrophoresis. American Journal of Analytical Chemistry, 5, 258-265. http://dx.doi.org/10.4236/ajac.2014.54032

[12] Akter, H., Shaikh, A.A., Chowdhury, T.R., Rahman, M.S., Bakshi, P.K. and Ahammad, A.J.S. (2013) Gold Nanoparticle-Modified Indium Tin Oxide Electrode for Highly Sensitive Electrochemical Detection of Melamine. ECS Electrochemistry Letters, 2, B13-B15. http://dx.doi.org/10.1149/2.001309eel

[13] Yue, J., Jiang, X., Kaneti, Y.V. and Yu, A. (2012) Deposition of Gold Nanoparticles on $\beta$-FeOOH Nanorods for Detecting Melamine in Aqueous Solution. Journal of Colloid and Interface Science, 367, 204-212. http://dx.doi.org/10.1016/j.jcis.2011.10.024

[14] Bai, L.Y., Dong, C.X., Zhang, Y.P., Li, W. and Chen, J. (2011) Comparative Studies on the Quick Recognition of Melamine Using Unmodified Gold Nanoparticles and p-Nitrobenzenesulfonic Grafted Silver Nanoparticles. Journal of Chinese Chemical Society, 58, 846-852. http://dx.doi.org/10.1002/jccs.201190134

[15] Zeng, S., Cai, M., Liang, H. and Hao, J. (2012) Size-Dependent Colorimetric Visual Detection of Melamine in Milk at 10 ppb Level by Citrate-Stabilized Au Nanoparticles. Analytical Methods, 4, 2499-2505. http://dx.doi.org/10.1039/c2ay25319d

[16] Chi, H., Liu, B., Guan, G., Zhang, Z. and Han, M.Y. (2010) A Simple, Reliable and Sensitive Colorimetric Visualization of Melamine in Milk by Unmodified Gold Nanoparticles. Analyst, 135, 1070-1075. http://dx.doi.org/10.1039/c000285b

[17] Adams, R.N. (1958) Carbon Paste Electrodes. Analytical Chemistry, 30, 1576. http://dx.doi.org/10.1021/ac60141a600

[18] Kalcher, K., Kauffmann, J.M., Wang, J., Svancara, I., Vytras, K., Neuhold, C. and Yang, Z. (1994) Sensors Based on Carbon Paste in Electrochemical Analysis: A Review with Particular Emphasis on the Period 1990-1993. Electroanalysis, 7, 5-22. http://dx.doi.org/10.1002/elan.1140070103

[19] Svancara, I. and Vytras, K. (1994) Preparation and Properties of Carbon Paste Electrodes. Chemicke Listy, 88, 138146.

[20] Sahoo, S., Satpati, A.K. and Reddy, A.V.R. (2010) Voltammetric Determination of Trace Levels of Hg in Ayurvedic Medicine and in Cobalt-Containing Samples Using a Carbon Paste Electrode. Analytical Science, 26, 1309-1312. http://dx.doi.org/10.2116/analsci.26.1309

[21] Dey, M.K., Satpati, A.K., Sahoo, S., Kameswaran, R., Reddy, A.V.R. and Mukherjee, T. (2011) Bi-Film on a Carbon Paste Electrode Modified with Nafion Film Embedded with Multiwall Carbon Nano Tubes for the Determination of Heavy Metals. Analytical Methods, 3, 2540-2546. http://dx.doi.org/10.1039/c1ay05339f

[22] Satpati, A.K. and Bard, A.J. (2012) Preparation and Characterization of Carbon Powder Paste Ultramicroelectrodes as Tips for Scanning Electrochemical Microscopy Applications. Analytical Chemistry, 84, 9498-9504.

[23] Ping, J.G., Yu, B., Xin, C.Z., Yu, C.X., Ming, Z. and Chang, Z. (2010) Electrochemical Behaviors and Determination of Melamine in Neutral and Acid Aqueous Media. Journal of Solid State Electrochemistry, 15, 2653-2659. http://dx.doi.org/10.1007/s10008-010-1249-8 
Scientific Research Publishing (SCIRP) is one of the largest Open Access journal publishers. It is currently publishing more than 200 open access, online, peer-reviewed journals covering a wide range of academic disciplines. SCIRP serves the worldwide academic communities and contributes to the progress and application of science with its publication.

Other selected journals from SCIRP are listed as below. Submit your manuscript to us via either submit@scirp.org or Online Submission Portal.
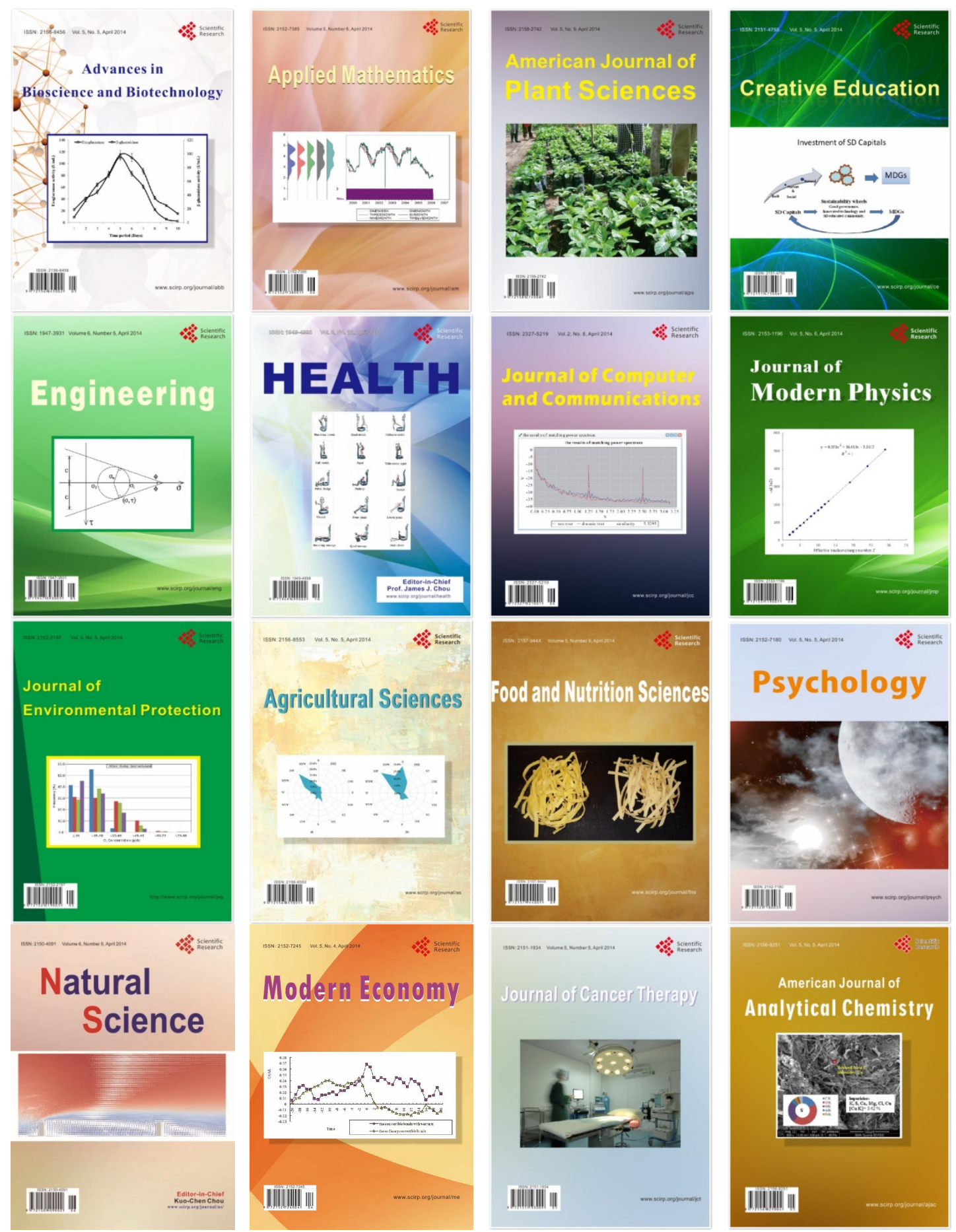